\title{
Immunogold localization of GyrA and GyrB proteins in Escherichia coli
}

\author{
M. Thornton, ${ }^{1}$ M. Armitage, ${ }^{1}$ A. Maxwell, ${ }^{2}$ B. Dosanjh, ${ }^{2} \dagger$ A. J. Howells, ${ }^{2}$ \\ V. Norris ${ }^{3}$ and D. C. Sigee ${ }^{1}$
}

Author for correspondence: D. C. Sigee. Tel: +4461275 3906. Fax: +4461275 5656.

1 School of Biological Sciences, University of Manchester, UK

2,3 Departments of Biochemistry ${ }^{2}$ and Microbiology ${ }^{3}$, University of Leicester, UK

\begin{abstract}
Immunogold preparations of Escherichia coli, using anti-GyrA and anti-GyrB antibodies to the subunits of DNA gyrase, showed clear labelling with both secondary antibody and protein A-gold conjugates. Both proteins were located mainly in the cytoplasm, with typically less than $10 \%$ in the nucleoid. This partitioning of gyrase proteins between nucleoid and cytoplasm was nonrandom and was consistently observed for a range of different cell preparations. Total gold particle counts were highly variable but suggested levels of at least 1000-3000 molecules per cell for both GyrA and GyrB. Sequential treatment with both anti-GyrA and anti-GyrB monoclonal antibodies resulted in simultaneous labelling of both proteins and revealed no clear association between the two groups of molecules. Treatment of cells with chloramphenicol caused marked changes in nucleoid conformation, but no reduction in cytoplasmic labelling of gyrase proteins. On the assumption that gyrase complexes within the nucleoid are not differentially masked from the monoclonal antibodies, the results obtained in this study suggest that most of the gyrase proteins are not associated with either central nucleoid DNA or cytoplasmic loops of peripheral single-stranded DNA, but are distributed randomly throughout the cytoplasm.
\end{abstract}

Keywords: Escherichia coli, DNA gyrase, immunogold localization, monoclonal antibodies

\section{INTRODUCTION}

DNA gyrase (prokaryotic topoisomerase II) introduces negative supercoils into bacterial DNA using the free energy of ATP hydrolysis (see Reece \& Maxwell, 1991, for a recent review). The enzyme from Escherichia coli consists of two subunits, $\mathrm{A}$ and $\mathrm{B}$, of molecular masses 97 and $90 \mathrm{kDa}$, respectively. The active enzyme is associated with DNA as an $A_{2} B_{2}$ complex, in which the $A$ subunit (GyrA) is thought to be principally concerned with the breakage and reunion of the DNA, while the $B$ subunit (GyrB) is the site of ATP hydrolysis. The enzyme is the target of two major groups of antibacterial agents, the quinolones and the coumarins.

On the basis of inhibition studies with the quinolone drug oxolinic acid, Snyder \& Drlica (1979) have estimated the number of active DNA gyrase sites at about 50 per cell.

†Present address: Department of Chemistry, University of York, UK. Abbreviation: mAb, monoclonal antibody.
This number corresponds approximately with the number of supercoiled domains identified by Worcel \& Burgi (1972) from sedimentation studies, suggesting that one DNA gyrase complex may be associated with each domain of supercoiling. If this is correct, then DNA gyrase might be expected to be localized at the nucleoid periphery, where supercoiled DNA domains spread out (Kavenoff \& Ryder, 1976) into the surrounding cytoplasm (Bohrmann et al., 1991).

The work described here was carried out to determine the location of the DNA gyrase proteins GyrA and GyrB in exponentially growing cells of $E$. coli using electron microscope immunogold labelling with appropriate monoclonal antibodies. Aspects to be investigated included the distribution of these proteins between nucleoid and cytoplasm, associations of GyrA and GyrB molecules with each other and with DNA, total numbers of these molecules in the cell, and the effect of the antibiotic chloramphenicol on their occurrence.

Immunogold labelling has the potential to provide detailed information at the cellular level (Beesley, 1985; 
Horisberger, 1992). This high resolution technique has been used previously to determine the location of other $E$. coli proteins associated with DNA such as H-NS (Durrenberger et al., 1991; Spurio et al., 1992), HU, DNA topoisomerase I and RNA polymerase (Durrenberger $e t$ al., 1988), proteins not associated with DNA (Cloeckaert et al., 1992; Bukua et al., 1993; Kroncke et al., 1990) and single-stranded DNA itself (Hobot et al., 1987).

\section{METHODS}

Cell culture and processing. Cells of E. coli (Manchester Culture Collection ref 301) were routinely cultured in nutrient broth at $37^{\circ} \mathrm{C}$ and sample at mid-log exponential phase $\left(10^{8}\right.$ cells $\left.\mathrm{ml}^{-1}\right)$. In preliminary experiments, cells were also cultured at $25^{\circ} \mathrm{C}$, where growth is slower and the central nucleotide more distinct. For chloramphenicol (Sigma) treatment, the antibiotic was dissolved in $100 \%$ ethanol and added to a $1.5 \mathrm{~h}, 37^{\circ} \mathrm{C}$ culture to produce a final concentration of $50 \mu \mathrm{g} \mathrm{ml}^{-1}$ and the culture sampled after $90 \mathrm{~min}$. As a control, cells were grown in parallel, with the addition of an equal volume of ethanol not containing antibiotic.

Cells were collected as a pellet by centrifugation at $20000 \mathrm{~g}$ for $10 \mathrm{~min}$, then resuspended for $10 \mathrm{~min}$ in one of the following fixatives: (a) $4 \%$ (v/v) paraformaldehyde plus $0.05 \%$ glutaraldehyde in $0.1 \mathrm{M}$ sodium cacodylate buffer, $\mathrm{pH} 7 \cdot 2$; (b) $2.5 \%$ $(\mathrm{v} / \mathrm{v})$ glutaraldehyde in sodium cacodylate buffer; or (c) acetic alcohol (absolute ethanol/glacial acetic acid, 3:1, v/v). Cells were subsequently processed either for cryosections or for res in embedding.

Cryosections. After aldehyde fixation ( $\mathrm{a}$ and $\mathrm{b}$ ), cells were washed in cacodylate buffer containing $2.3 \mathrm{M}$ sucrose, pelleted, then plunge-frozen in liquid propane at $-196^{\circ} \mathrm{C}$. Ultrathin sections were cut at $-70^{\circ} \mathrm{C}$ and immediately used for immunolabelling.

Resin sections. After fixation, cells were washed in cacodylate buffer (fixatives a and b) or absolute ethanol (fixative c) prior to embedding in Lowicryl HM20 or K4M resin. Resin embedding from aldehyde fixatives involved sequential dehydration in an ethylene glycol series followed by resin infiltration and UV polymerization at $-50{ }^{\circ} \mathrm{C}$ ( $\mathrm{HM} 20$ resin) or $-30{ }^{\circ} \mathrm{C}(\mathrm{K} 4 \mathrm{M}$ resin), according to standard procedures (Hobot \& Newman, 1991).

\section{Immunolabelling}

Monoclonal antibodies. A series of mouse monoclonal antibodies (mAbs) have been raised against GyrA and GyrB (M. Gellert \& A. Maxwell, unpublished results). Antibodies were purificd from ascites preparations by standard procedures (Harlow \& Lane, 1988) to $>90 \%$ homogeneity. In these experiments, three antibodies were used: $7 \mathrm{~F} 11$ (anti-GyrA, $\operatorname{IgG}_{2 \mathrm{~b}}$ ), 7D3 (antiGyrB, $\operatorname{IgG}_{2 \mathrm{~b}}$ ) and $10 \mathrm{C5}$ (anti-GyrB, IgM). Western blotting experiments were performed as described by Harlow \& Lare (1988).

Two-step labelling procedure. Immunolabelling was carried out on cryo- or resin sections according to standard procedures (Hobot, 1989), as follows. (1) Pretreatment for 2 min with $1 \%$ bovine serum albumin in PBS containing $0.05 \%$ Tween 20 (BSA/PBS medium). (2) $\mathrm{mAb}$ diluted $\frac{1}{3}$ with BSA/PBS $(1 \mathrm{~h})$.
(3) Rinse for $5 \mathrm{~min}$ in PBS. (4) Gold probe diluted $\frac{1}{3}$ in BSA/PBS $(1 \mathrm{~h})$. The gold probe was conjugated either with goat anti-mouse secondary antibody (Bioclinical Services) or with protein A (Sigma). (5) Rinse for 2 min in PBS. (6) Staining with $2 \%$ uranyl acetate for 10 min followed by $2 \%(\mathrm{w} / \mathrm{v})$ alkaline lead citrate for $3 \mathrm{~min}$.

Control experiments for specificity of labelling were carried out as detailed in the Results section.

Double labelling. Simultaneous labelling of both subunits was carried out by one of two methods.

(a) Secondary antibodies. Ultrathin sections were labelled with separate $\operatorname{IgG}$ and $\operatorname{IgM} \mathrm{mAbs}$, followed by anti-mouse-IgG and -IgM secondary antibodies conjugated to $10 \mathrm{~nm}$ and $20 \mathrm{~nm}$ gold probe particle sizes, respectively. Labelling was carried out in sequence and on the same side of the resin section, with the $\operatorname{Ig} G$ $\mathrm{mAb} / 10 \mathrm{~nm}$ probe first, followed by a $5 \mathrm{~min}$ wash in PBS then the $\operatorname{IgM} \mathrm{mAb} / 20 \mathrm{~nm}$ probe.

(b) Protein A. Sections were labelled with one $\mathrm{mAb}$, followed by protein $\mathrm{A}-10 \mathrm{~nm}$ gold conjugate, as described previously. The EM grids were then floated onto droplets of protein A (to saturate all attached antibodies), washed in PBS, then treated with the second $\mathrm{mAb}$ and $20 \mathrm{~nm}$ gold protein $\mathrm{A}$ as above.

Electron microscopy and analysis. Immunopreparations were examined in an AEI801 or Hitachi 600 electron microscope. For quantitative analysis of individual preparations, 10 cells in longitudinal section were selected at random, photographed at a magnification of 30000 and printed to give a final enlargement of 100000 . The occurrence of gold probe particles was analysed in terms of compartmental localization, distribution from the nucleoid boundary and nearest neighbour distances.

Compartmental localization. Gold probe particles were counted over the three major cell compartments, cell surface complex (inner membrane/periplasm/outer membrane), electron-dense cytoplasm and electron-transparent nucleoid. Background counts were made over areas of resin near to bacterial cells. Areas occupied by the different cellular compartments were determined morphometrically by placing a $10 \mathrm{~nm}$-square lattice over individual bacterial profiles and making point counts. The areas of the different compartments were used to estimate the proportions of gold particle counts that would have arisen on a random basis and the number of gold particle counts in a compartment that would have arisen due to background.

Nucleoid boundary. Minimum distances between each gold probe particle and the nearest point on the nucleoid/cytoplasmic boundary were determined for both nucleoid and cytoplasmic particles and expressed as a histogram. Equal numbers of random points were plotted (from random number tables) over a plan of the cell using a $10 \mathrm{~nm}$-square lattice, and similar calculations performed. Gold particle and random point distributions were compared to determine if there was any nonrandom localization around the nucleoid boundary.

Nearest neighbour distances. Spatial associations between the $20 \mathrm{~nm}$ and $10 \mathrm{~nm}$ gold particles in the double labelling preparations were examined by nearest neighbour analysis. The distance between each $20 \mathrm{~nm}$ particle and the nearest $10 \mathrm{~nm}$ particle was measured and plotted as a cumulative histogram. Two separate random point distributions were then plotted over a map of the cell, corresponding to the $20 \mathrm{~nm}$ and $10 \mathrm{~nm}$ particle distributions (i.e. equal numbers of random points plotted over $20 \mathrm{~nm}$ - and $10 \mathrm{~nm}$-square lattices, respectively). Distances between $20 \mathrm{~nm}$ and $10 \mathrm{~nm}$ points were measured as 


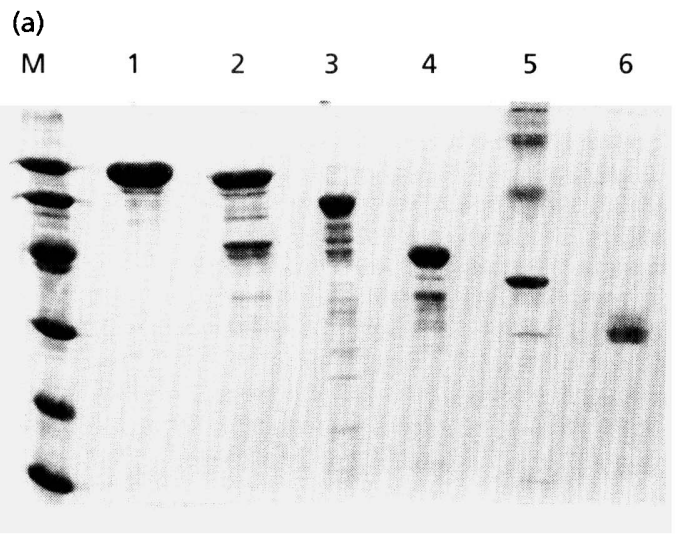

(c)

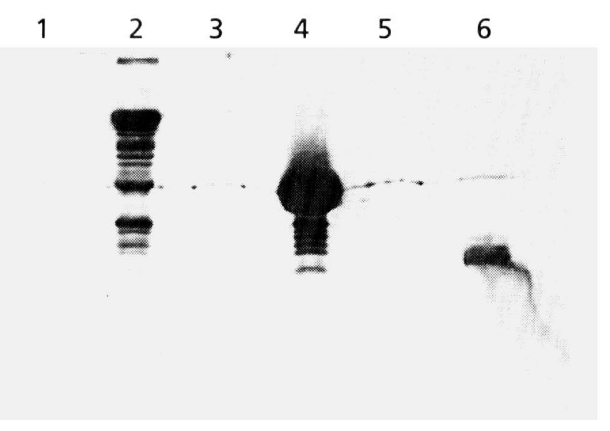

(b)

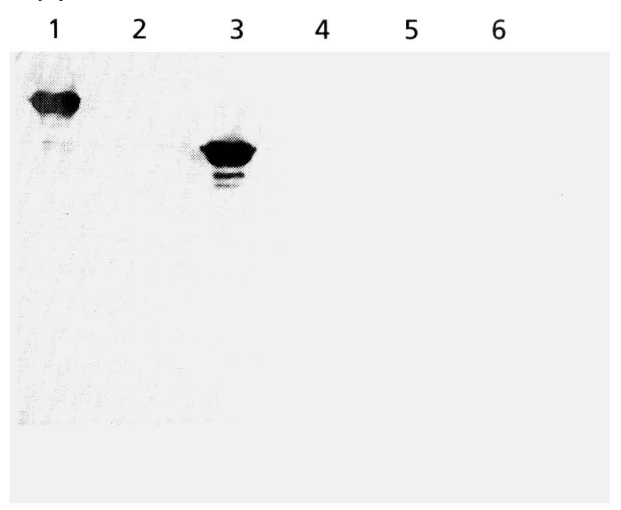

(d)

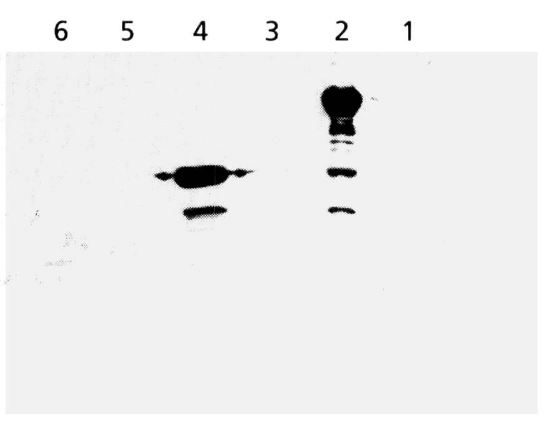

Fig. 1. Specificities of mAbs. Panel (a) shows an SDS-polyacrylamide gel which was subsequently blotted and probed with mAbs 7F11 (b), 7D3 (c) and 10C5 (d). Gel tracks contain the following gyrase proteins: 1, GyrA (97 kDa); 2, GyrB (90 kDa); 3, $64 \mathrm{kDa} \mathrm{N}$-terminal domain of GyrA; 4, $43 \mathrm{kDa} \mathrm{N}$-terminal domain of GyrB; $5,33 \mathrm{kDa}$ C-terminal domain of GyrA; 6, $24 \mathrm{kDa} N$-terminal sub-domain of GyrB. $\mathrm{M}$, molecular mass markers: phosphorylase b $(94 \mathrm{kDa})$; bovine serum albumin $(67 \mathrm{kDa})$; ovalbumin $(43 \mathrm{kDa}) ;$ carbonic anhydrase $(30 \mathrm{kDa})$; soybean trypsin inhibitor $(20.1 \mathrm{kDa}) ; \alpha$-lactalbumin $(14.4 \mathrm{kDa})$.

previously described, and the histogram compared to the gold particlc data.

\section{RESULTS}

\section{mAbs}

Prior to the immunolabelling experiments, the specificity of each $\mathrm{mAb}$ was determined in Western blotting experiments. The gel tracks contained both intact GyrA and (jyrB proteins plus N-terminal and C-terminal domans of these molecules (Fig. 1). From these data it is clear that $\mathrm{mAb} 7 \mathrm{~F} 11$ is specific for GyrA, while mAbs $7 \mathrm{D} 3$ and $10 \mathrm{C} 5$ are specific for GyrB. In each case the $\mathrm{mAb}$ is specitic for the N-terminal part of the protein.

In other experiments we have shown that the antibodies can recognize the $G y r A$ and $G y r B$ proteins under native conditions in an $\mathrm{A}_{2} \mathrm{~B}_{2}$ complex with DNA, as manifested by their ability to inhibit a range of gyrase activities in vitro (data not shown). In addition, we have found that in gel retardation assays (Maxwell \& Gellert, 1984) the binding of these antibodies leads to the formation of a slowermoving band behind the gyrase- DNA complex band. For example, with antibody 7D3 a complex between the antibody and the gyrase-DNA complex can be formed whether the antibody is pre-incubated with GyrA or GyrB, or is added directly to a preformed $A_{2} B_{2}-D N A$ complex (data not shown).

\section{Cell preparation - qualitative aspects}

As a preliminary study, a range of preparative techniques were carried out, involving both cryo- and resin sections and a range of fixation procedures (see Methods). Different types of preparation were expected to lead to differences in preservation of epitopes as well as variations in ultrastructural appearance.

Cryosections were taken from cells that had been fixed in paraformaldehyde or glutaraldehyde but had not been chemically dehydrated or resin-infiltrated. The two types of fixation resulted in a closely similar fine structural appearance, with the nucleoid dispersed throughout the cell, but only in the case of paraformaldehyde were the epitopes preserved. Using the anti-GyrA mAb 7F11, immunogold label was detected almost exclusively over the electron-dense cytoplasm, with little nucleoid labelling.

Initial studies with Lowicryl HM20-embedded cells involved both coagulative (acetic alcohol) and additive 
Table 1. Distribution of gold probe in paraformaldehyde-fixed resin-embedded cells

Cells were embedded in Lowicryl HM20 resin. Gold counts are the cumulative value from 10 cells in longitudinal section. Percentage and area fraction data are the overall values from these cells. Counts were corrected for background, which typically contributed about $5 \%$ of the uncorrected cytoplasmic count.

\begin{tabular}{|c|c|c|c|c|}
\hline & Nucleoid & Cytoplasm & $\begin{array}{l}\text { Surface } \\
\text { complex }\end{array}$ & Total \\
\hline \multicolumn{5}{|l|}{$25^{\circ} \mathrm{C}$-grown cells } \\
\hline Gold probe count & 245 & 981 & 4 & 1230 \\
\hline Percentage & 20 & 80 & 0 & \\
\hline Area fraction $(\%)$ & 29 & 60 & 11 & \\
\hline \multicolumn{5}{|l|}{$\mathrm{mAb} 7 \mathrm{D} 3$ anti-GyrB IgG2b (10 nm probe) } \\
\hline Gold probe count & 58 & 410 & 3 & 471 \\
\hline Percentage & 12 & 87 & 0 & \\
\hline Area fraction $(\%)$ & 21 & 64 & 15 & \\
\hline \multicolumn{5}{|l|}{$37^{\circ} \mathrm{C}$-grown cells } \\
\hline Gold probe count & 87 & 607 & 33 & 727 \\
\hline Percentage & 12 & 83 & 5 & \\
\hline Area fraction $(\%)$ & 32 & 58 & 10 & \\
\hline \multicolumn{5}{|l|}{ mAb 7D3 anti-GyrB IgG2b (10 nm probe) } \\
\hline Gold probe count & 27 & 370 & 27 & 424 \\
\hline Percentage & 6 & 87 & 6 & \\
\hline Area fraction $(\%)$ & 20 & 64 & 17 & \\
\hline \multicolumn{5}{|l|}{$\mathrm{mAb} 10 \mathrm{C} 5$ anti-GyrB IgM (20 nm probe) } \\
\hline Gold probe count & 14 & 235 & 19 & 268 \\
\hline Percentage & 5 & 88 & 7 & \\
\hline Area fraction $(\%)$ & 30 & 62 & 8 & \\
\hline
\end{tabular}

Table 2. Protein A labelling of Lowicryl HM20-embedded cells

Grain counts are derived from 10 cells and corrected for background.

\begin{tabular}{|ccccc|}
\hline & Nucleoid & Cytoplasm & $\begin{array}{c}\text { Surface } \\
\text { complex }\end{array}$ & Total \\
\hline mAb 7F11 & & & & \\
Gold probe count & 95 & 658 & 36 & 789 \\
Percentage & 12 & 83 & 5 & \\
Area fraction (\%) & 29 & 71 & 10 & \\
mAb 7D3 & & & & 763 \\
Gold probe count & 140 & 596 & 27 & \\
Percentage & 18 & 78 & 4 & \\
Area fraction (\%) & 19 & 66 & 15 & \\
Control - no mAb & & & & \\
Gold probe count & 6 & 70 & 5 & \\
Percentage & 7 & 86 & 6 & \\
Area fraction (\%) & 10 & 73 & 17 & \\
\hline
\end{tabular}

(paraformaldehyde, glutaraldehyde) fixatives. Although acetic alcohol fixation does not lead to optimal preservation of cell fine structure, it does result in good retention of GyrA and GyrB epitopes - with immunogold particles localized to electron-dense cytoplasm around the dispersed nucleoid. As with the cryosectioned 
Table 3. Labelling of Lowicryl K4M resin-embedded cells

Primary antibody: 7D3. Probe counts are corrected for background and are derived from 10 cells.

\begin{tabular}{|ccccc|}
\hline & Nucleoid & Cytoplasm & $\begin{array}{c}\text { Surface } \\
\text { complex }\end{array}$ & Total \\
\hline Protein A & & & & \\
Gold probe count & 580 & 3808 & 71 & 4459 \\
Percentage & 13 & 85 & 2 & \\
Area fraction (\%) & 21 & 72 & 7 & \\
Secondary antibody & & & & \\
Gold probe mean count & 108 & 1232 & 21 & 1361 \\
Percentage & 8 & 91 & 2 & \\
Area fraction (\%) & 17 & 75 & 8 & \\
\hline
\end{tabular}

Table 4. Distribution of label in chloramphenicol-treated cells

Gold particle counts are expressed as the mean per cell, derived from 10 cells and corrected for background. Cells were embedded in Lowicryl K4M resin.

\begin{tabular}{|ccccc|}
\hline & Nucleoid & Cytoplasm & $\begin{array}{c}\text { Surface } \\
\text { complex }\end{array}$ & Total \\
\hline mAb 7F11 & & & & \\
Gold probe mean count & 9 & 246 & 6 & 261 \\
Percentage & 3 & 94 & 3 & \\
Area fraction (\%) & 21 & 69 & 10 & \\
mAb 7D3 & & & & \\
Gold probe mean count & 8 & 56 & 2 & \\
Percentage & 12 & 85 & 3 & \\
Area fraction (\%) & 28 & 59 & 13 & \\
\hline
\end{tabular}

cells, paraformaldehyde-fixed cells showed a high level of immunogold labelling, but glutaraldehyde-fixed cells showed no significant labelling at all.

\section{Paraformaldehyde fixation}

Fixation in paraformaldehyde, with embedding in Lowicryl HM20 or K4M resin, was selected as the most appropriate method of cell preparation, both in terms of fine structural preservation and retention of epitopes. Cells were grown at $25{ }^{\circ} \mathrm{C}$ (slow growing - moderately condensed nucleoid) and at $37^{\circ} \mathrm{C}$ (fast growing dispersed nucleoid), and a range of $\mathrm{mAbs}$ used. Results are summarized in Tables 1-4 and illustrated in Fig. 2.

\section{Secondary antibody labelling - HM20 resin}

The general level of labelling, expressed as mean background-corrected counts per cell, varied considerably between different $\mathrm{mAbs}$, and also between different preparations using the same antibody. Over five or more separate experiments, the mean corrected count ranged from 65 to 280 grains per cell (mean 180) for mAb 7F11 and 25 to 60 (mean 40) for 7D3. Clear differences between 7F11 and 7D3 can be seen in Tables 1 and 4. mAb 10C5 was used less frequently, but gave similar levels to $7 \mathrm{D} 3$, suggesting that the anti-GyrB mAbs were labelling fewer epitopes than the anti-GyrA mAb.

Although the overall level of labelling was variable, distribution within the cell followed a well-defined pattern. For all preparations, approximately $80-90 \%$ of the gold probe counts occurred in the cytoplasm and $5-20 \%$ in the nucleoid (Table 1). Levels in the surface complex were normally less than $5 \%$ and were considered negligible.

Cells grown at $25^{\circ} \mathrm{C}$ typically had a more condensed nucleoid compared to those cultured at $37^{\circ} \mathrm{C}$. The distribution of GyrA and GyrB proteins was substantially similar at both temperatures, though there is some indication of slightly higher nucleoid levels at the lower temperature (Table 1).

Comparison to random. If the distribution of gold particles over bacterial sections was random, their number within a particular compartment would be directly proportional to its area. Comparison of percentage gold 

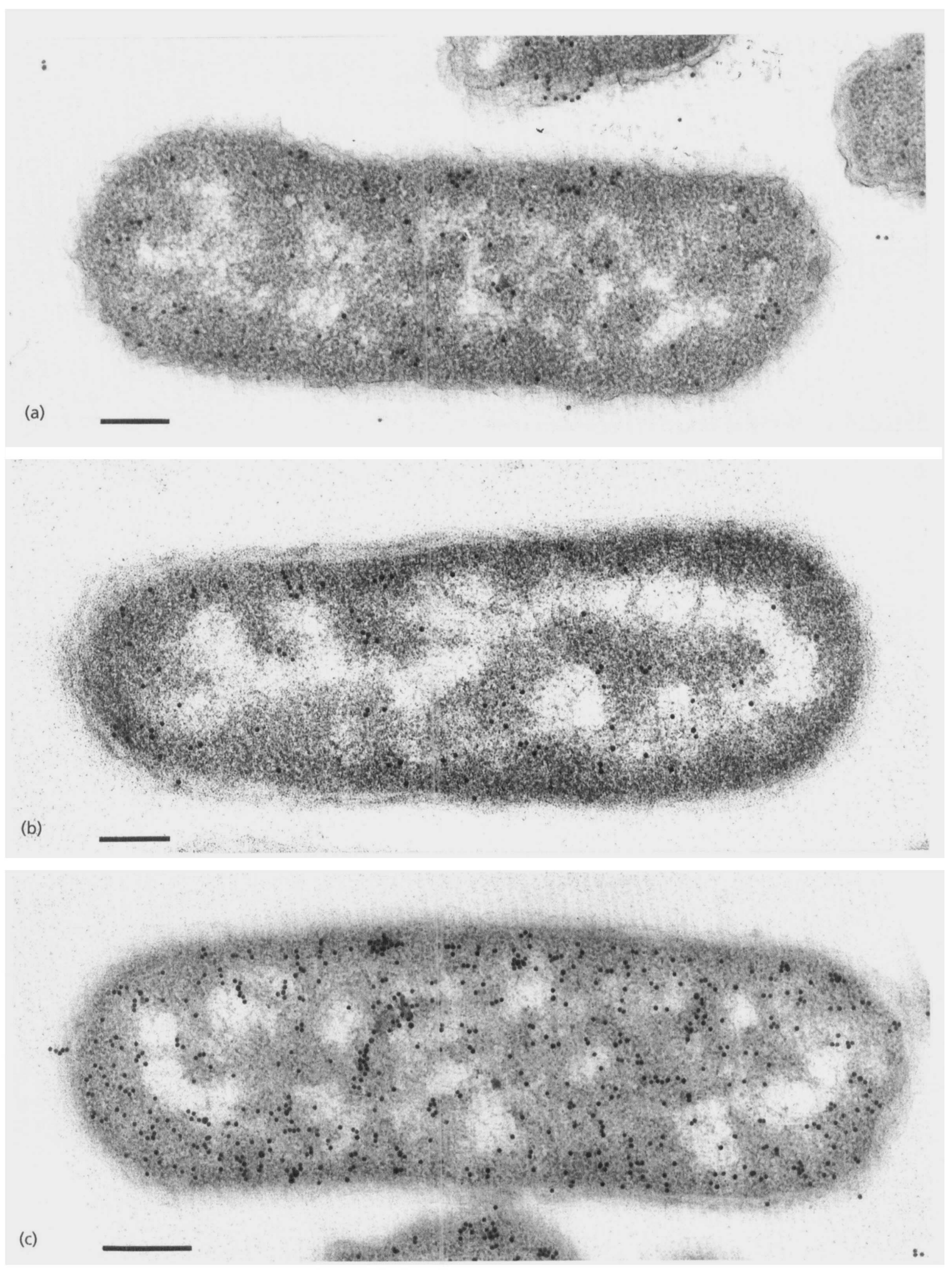

Fig. 2. Immunolabelling of bacterial cells grown at $37^{\circ} \mathrm{C}$. All cells are fixed in paraformaldehyde, and embedded in Lowicryl HM20 (a) or K4M (b, c) resin. With each preparation the gold probe size was $10 \mathrm{~nm}$. Bar, $0.25 \mu \mathrm{m}$. (a) mAb 7F11 (anti-GyrA); secondary antibody probe. (b) mAb 7D3 (anti-GyrB); secondary antibody probe. (c) mAb 7D3 (anti-GyrB); protein A probe. 

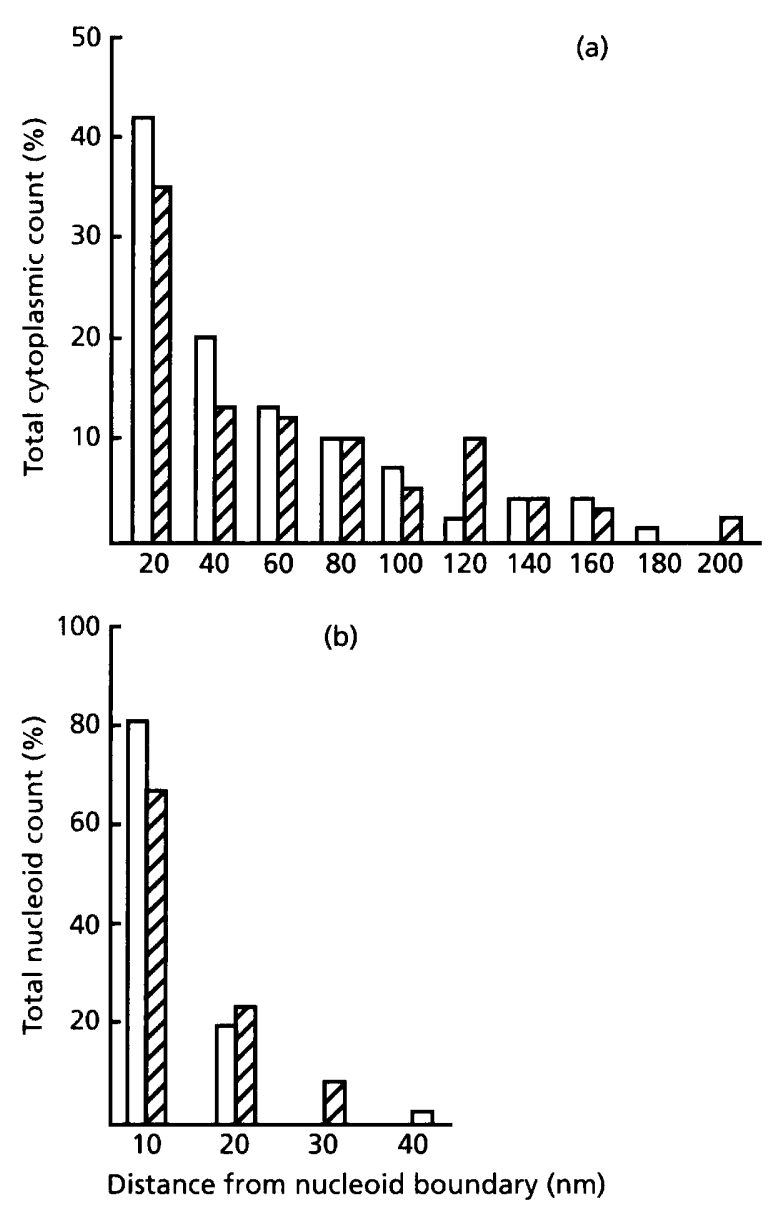

Fig. 3. Cumulative distances of gold particles (immunogold preparation) and random points in relation to nucleoid boundary. Histograms are derived from three separate mAb 7F11-labelled bacterial sections, with an overall total of 190 cytoplasmic and 26 nucleoid gold particles. Distributions are recorded as percentage total cytoplasmic (a) and nucleoid (b) counts, respectively. $\square$, Probe; 荡, random.

particle counts and percentage area counts were made for all preparations. The percentage occurrence of gold particles over cytoplasm was invariably higher than its percentage area (Tables $1-3$ ), confirming a clear localization to this part of the cell (i.e. gold counts per unit area cytoplasm were higher than per unit area nucleoid).

Comparison of GyrA and GyrB labelling. The pattern of labelling for both proteins was broadly similar (Table 1), suggesting that these have similar distributions within the cell. The pattern is also similar for the anti-IgG and antiIgM probes against $\mathrm{GyrB}$, indicating that the immunoglobulin class of the primary and secondary antibody does not influence the observed localization of the target molecule.

Controls. The specificity of labelling was determined by control experiments using secondary antibodies (gold conjugates) without primary $\mathrm{mAb}$ pretreatment, pretreatment with non-specific mouse $\mathrm{IgG}$ and pretreatment with the $\mathrm{mAb}$ of the wrong $\operatorname{IgG} / \operatorname{IgM}$ type. In no case was detectable labelling (i.e. significantly greater than background) observed.

\section{Protein A labelling - HM20 resin}

Protein A-gold labelling of Lowicryl HM20 sections (Table 2) resulted in a similar pattern to that seen previously, with higher levels over the cytoplasm compared to the nucleoid. Control preparations (without $\mathrm{mAb}$ ) showed a marked reduction in grain count, but there was some residual low-level labelling of all cell compartments which reduced the specificity of this probe.

\section{Secondary antibody and protein A labelling with K4M resin}

The use of hydrophilic $\mathrm{K} 4 \mathrm{M}$ resin as the embedding medium typically resulted in considerably higher grain counts compared to HM20. Typical results are shown in Table 3, where the mean corrected grains counts were 136 per cell for secondary antibody and 446 per cell for protein $A$, respectively. These values are much higher than previously obtained with mAb 7D3 for HM20 resin. The intracellular distribution of gold particles was similar to the HM20-embedded cells (Figs $2 \mathrm{~b}$ and c) with $85-90 \%$ occurring over cytoplasm and about $10 \%$ over nucleoid.

\section{Distribution of gold particles in relation to nucleoid boundary}

The distribution of gold particles over the cytoplasm of selected bacterial cells was examined in relation to the nucleoid boundary by measuring the minimum distances of individual particles to the boundary and plotting a histogram (Fig. 3a). This was then compared to a random point distribution (Fig. 3a) as described in Methods. A similar combined histogram was also plotted for nucleoid gold particles and random points.

The histogram of cytoplasmic distributions (Fig. 3a) shows a clear clustering of gold particles in relation to the nucleoid boundary. This largely reflects cell topography, however, and does not imply a localized distribution of GyrA and GyrB proteins to this part of the cell since a closely similar distribution occurs for points distributed randomly throughout the cytoplasm. General comparison of the two distributions indicates that most of the GyrA and $\mathrm{GyrB}$ proteins are dispersed throughout the cytoplasm in a random manner, over distances of 0-200 $\mathrm{nm}$ (in section) from the nucleoid boundary. Closer analysis of gold particle and random point distributions does suggest, however, that there is some limited non-random clustering close to the nucleoid/cytoplasmic interface. In the distributions shown in Fig. 3a, for example, just over $62 \%$ of the cytoplasmic gold particles occurred within $40 \mathrm{~nm}$ of the nucleoid boundary compared to $48 \%$ for the random distribution.

Within the nucleoid the low level of labelling makes assessment of particle distribution problematical. As with the previous histogram, both gold particle and random points show a clear clustering towards the boundary (Fig. 


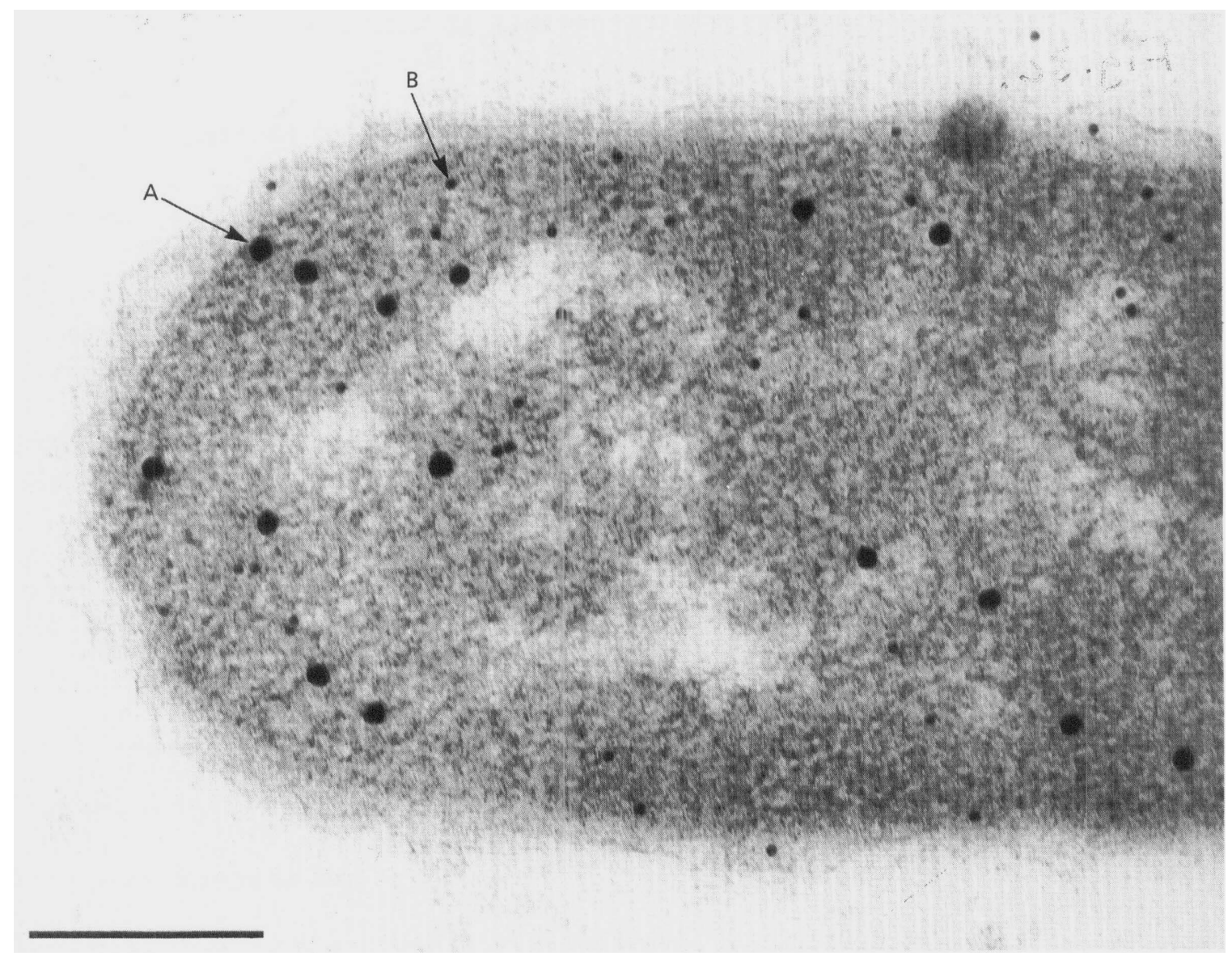

Fig. 4. Simultaneous labelling of GyrA and GyrB proteins. The double labelling results from application of $m A b$ 7D3 (antiGyrB) with protein A $10 \mathrm{~nm}$ probe, followed by $7 F 11$ (anti-GyrA) and protein A $20 \mathrm{~nm}$ probe. A, $20 \mathrm{~nm}$ particle; B, $10 \mathrm{~nm}$ particle. Bar, $200 \mathrm{~nm}$.

$3 \mathrm{~b})$, with higher proportions of immunolabel at the very edge of the nucleoid. The results shown in Figs 3(a) and (b) were typical of other cells analysed.

\section{Simultaneous labelling of GyrA and GyrB proteins}

Sequential treatment of sections with anti-GyrA and antiGyrB mAbs, in conjunction with protein $\mathrm{A}$ or secondary antibody gold conjugate probes, resulted in simultaneous labelling of both proteins within the cell.

Results obtained with mAb 7D3 (10 nm protein A-gold) followed by mAb 7F11 (20 nm protein A-gold) are shown in Fig. 4. The two sizes of gold particle appear to be scattered randomly throughout the cytoplasm, with no clear association. This would suggest that the majority of GyrA and GyrB proteins are distributed independently of each other.

Similar results were obtained when cells were sequentially labelled with $\mathrm{mAb} 7 \mathrm{~F} 11$ ( $10 \mathrm{~nm}$ anti-IgG secondary antibody) followed by $\mathrm{mAb} 10 \mathrm{C} 5$ (20 nm anti-IgM probe). This was further investigated by measuring the distances between $20 \mathrm{~nm}$ particles and the nearest $10 \mathrm{~nm}$ particle, and plotting nearest-neighbour distances as a frequency histogram. An equivalent histogram was plotted for random point distributions (see Methods). Composite histograms, derived from cytoplasmic counts of three separate cells, are shown in Fig. 5(a) (gold particles) and Fig. 5(b) (random points). Although there was a small overall tendency for more gold particle pairs to be in the range $0-80 \mathrm{~nm}$, this did not occur for each cell, and the two distributions were essentially similar. In both cases, the mean distance of separation was $60-80 \mathrm{~nm}$, with values up to $240 \mathrm{~nm}$. Comparison of gold particle separations with those of the random point distributions would thus suggest that there is no detectable association between GyrA and GyrB epitopes, and that the two proteins occur independently throughout the cytoplasm. Similar results, based on fewer counts, were obtained for nucleoid distributions.

\section{Chloramphenicol treatment}

Chloramphenicol-treated cells differed markedly from control cells (no chloramphenicol treatment) in having a fully condensed central nucleoid, with no nucleoid spaces 


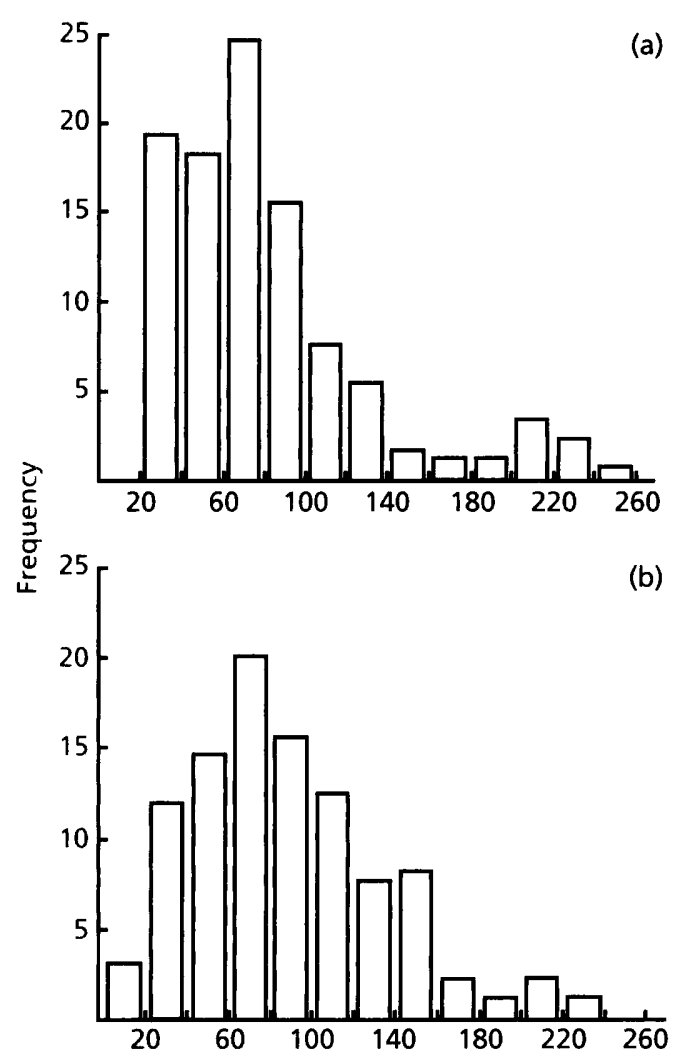

Distance between $10 \mathrm{~nm}$ and $20 \mathrm{~nm}$ particles $(\mathrm{nm})$

Fig. 5. Nearest-neighbour distance analysis between $10 \mathrm{~nm}$ and $20 \mathrm{~nm}$ gold particles (immunogold preparation) and equivalent random points. See Methods for details. Data are taken from three bacterial sections in a preparation labelled with mAb 7F11 (with anti-IgG secondary antibody, $10 \mathrm{~nm}$ gold conjugate) followed by $10 C 5$ (with anti-lgM secondary antibody, $20 \mathrm{~nm}$ gold conjugate). (a) Gold particle distribution. (b) Random point distribution.

in the peripheral cytoplasm. In some sections, the nucleoid appeared to be spherical (Fig. 6), while in others it had an annular shape, enclosing a cytoplasmic core.

Immuno-labelling with $\mathrm{mAbs} 7 \mathrm{~F} 11$ and 7D3 separately resulted in high frequencies of gold particles over the cytoplasm, with clear localization in both cases to this part of the cell (Table 4, Fig. 6). This distribution is closely similar to control cells (and to all experiments not involving chloramphenicol), indicating that although this antibiotic has a major effect on cell fine structure it has not altered the distribution of GyrA and GyrB proteins.

\section{DISCUSSION}

Labelling of $E$. coli sections with anti-GyrA and antiGyrB mAbs led to the immuno-detection of these proteins in both nucleoid and cytoplasm. The interpretation of these preparations depends on the specificity of labelling and the retention of epitopes during specimen preparation.

\section{Specificity of labelling}

The specificity of primary antibody labelling is shown by the clear results obtained from the Western blots. It is known that the GyrA and GyrB proteins are each organized into two functional domains (Reece \& Maxwell, 1991). The sizes of these domains are $64 \mathrm{kDa}(\mathrm{N}$ terminus) plus $33 \mathrm{kDa}$ (C terminus) in GyrA, and $43 \mathrm{kDa}$ ( $\mathrm{N}$ terminus) plus $47 \mathrm{kDa}$ (C terminus) in GyrB. In both cases it is the $\mathrm{N}$ terminus that is recognized by the antibodies.

Recognition of the primary antibody by the secondary antibody or protein A probes is also important. Protein A has a high affinity for certain IgG antibodies, reacting with the Fc region of the molecule (Horisberger, 1992). The specificity of labelling at the section surface was determined by a range of control experiments in which the primary antibody or gold conjugate probe were altered or omitted. Specificity was highest with secondary antibody probes (no significant label in absence of the $\mathrm{mAb}$ ), while protein A did have a low level of non-specific labelling.

\section{Preparation conditions}

Immunogold labelling occurred with bacterial cells that had been processed with coagulative or additive fixatives, embedded in different types (hydrophilic/hydrophobic) of resin or frozen and cryosectioned. This indicates that GyrA and GyrB epitopes were preserved under very different preparation situations and that their detection was to some degree independent of cell handling procedures. Conventional fixation with glutaraldehyde did, however, destroy or mask the epitopes, in line with results generally obtained by other workers. The consistent pattern of labelling obtained after different preparation conditions suggests that the observed gold particle distribution was not an artefact of cell processing.

\section{Distribution and localization of GyrA and GyrB proteins}

The cytoplasmic occurrence and localization of DNA gyrase proteins observed in this study parallels the results obtained for certain other DNA-binding proteins such as HU protein and DNA topoisomerase I (Durrenberger t al., 1988). The low level of nucleoid labelling under a range of preparation conditions provides clear evidence that gyrase is largely absent from this part of the cell. It should be noted, however, that nucleoid-associated gyrase might occur in complexes which mask the epitopes from the mAbs, so that under-detection in this part of the cell cannot be absolutely ruled out. Low nucleoid levels observed with DNA gyrase are in marked contrast to the occurrence of H-NS protein (Durrenberger et al., 1991; Spurio et al., 1992), which shows clear localization to the nucleoid.

The GyrA and GyrB proteins are presumably present within the cytoplasm as discrete DNA gyrase subunits, which may or may not be DNA-associated. Measurements 


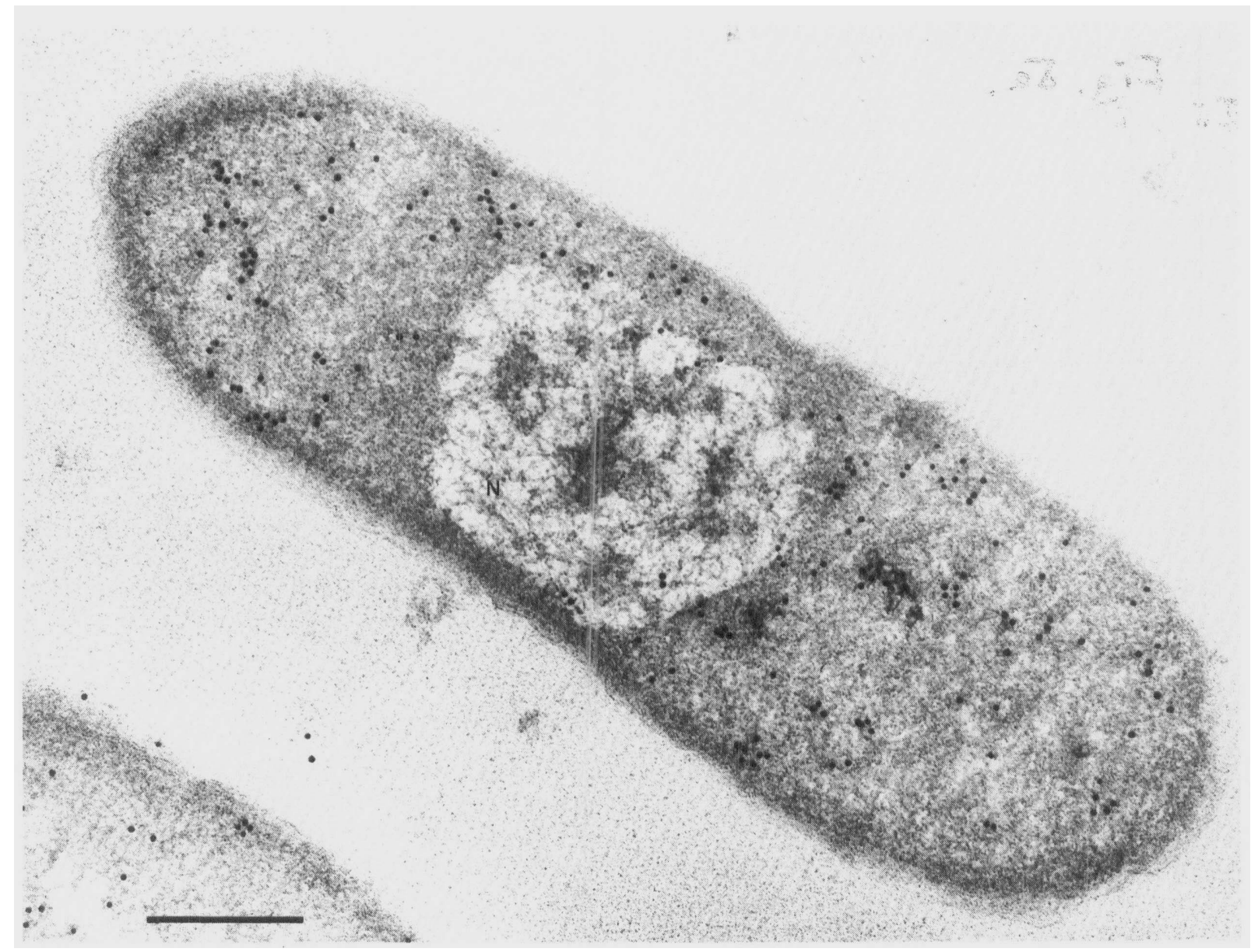

Fig. 6. Location of GyrA proteins in a chloramphenicol-treated cell. Low-power view of mAb 7F11-labelled cell with spherical condensed nucleoid $(\mathrm{N})$. Immunogold label is almost entirely in the peripheral dense cytoplasm. Bar, $0.25 \mu \mathrm{m}$.

of gold marker distributions in relation to the nucleoid boundary indicate that there is no general localization towards this part of the cell. This would suggest that most of the cytoplasmic gyrase proteins are not DNAassociated, since cytoplasmic (single-stranded) DNA is known to occur mainly at the nucleoid boundary (Hobot et al., 1987). This is consistent with the known lack of evidence for gyrase binding to ssDNA (Reece \& Maxwell, 1991).

\section{Total probe counts}

Although the distribution of gold particles within bacterial sections showed a constant pattern, total numbers of gold particles over cells (i.e. the degree of labelling) varied considerably. This was typically higher for $\mathrm{mAb} 7 \mathrm{~F} 11$ compared to 7D3 and 10C5, suggesting a higher detectability of GyrA compared to GyrB epitopes under these experimental conditions. The level of labelling was also typically higher for Lowicryl K4M compared to HM20 resin. Differences between resin can largely be attributed to their hydrophobicity (Hobot \& Newman, 1991), with greater penetration and labelling of internal epitopes in the case of hydrophilic (K4M resin). HM20 resin is strongly hydrophobic, with labelling restricted to epitopes exposed at the section surface.

Using secondary antibody-gold probes, levels of labelling reached as high as 280 particles per cell with $\mathrm{mAb} 7 \mathrm{~F} 11$ and 140 per cell with 7D3. On the assumption that all the GyrA and GyrB epitopes within the ultrathin section are labelled, and that the volume of bacterium within the longitudinal section occupies about one-tenth the volume of the whole cell, this would give overall levels of labelling of about 3000 epitopes per cell for $\mathrm{mAb} 7 \mathrm{~F} 11$ (GyrA) and 1500 for mAb 7D3 (GyrB). Even with K4M resin, it is unlikely that all epitopes within the section will be labelled, so these values are almost certainly conservative estimates. Higher grain counts were obtained with protein $\mathrm{A}$ in some preparations, but since these data also included a degree of non-specific labelling they are not included in these calculations.

The minimal estimates given above indicate levels of at least 1000-3000 molecules per cell of GyrA and GyrB. These may be compared to values obtained for other DNA-binding proteins in E. coli, with levels in the order 
of $10^{5}$ molecules per cell for ribosomal subunit protein $\mathrm{H}$ and $10^{4}$ molecules per cell for the histone-like proteins $\mathrm{HU}$ and H1 (Drlica \& Rouviere-Yaniv, 1987; Higgins et al., 1990 ).

\section{Associations between GyrA and GyrB proteins}

The results obtained in the double-labelling experiments suggest that GyrA and GyrB proteins are not coassociared into clear groups within the cytoplasm. This interpretation was based on experiments with both protein $A$ and secondary antibody-gold probes, and with sequences of both GyrA/GyrB and GyrB/GyrA labelling. In each case, the distribution of $10 \mathrm{~nm}$ and $20 \mathrm{~nm}$ gold particles suggested that the GyrA and GyrB proteins were distributed randomly and independently. Although no evidence of general co-association was found, the results do not preclude the existence of a small subpopulation of complexes (e.g. $\mathrm{A}_{2} \mathrm{~B}_{2}$ ), since double labelling of aggregates might be limited by orientation within the resin or by the gold probe size.

\section{Chloramphenicol treatment}

Studies by Hobot et al. (1987) have shown that treatment with chloramphenicol leads to major changes in the conformation of the bacterial nucleoid. This becomes visibly condensed at the centre of the cell, with singlestranded DNA (ssDNA) migrating from the cytoplasm and becoming localized to the nucleoid region (as determined by immunogold labelling). In these cells the cytoplasm has largely lost the peripheral loops of ssDNA, which are involved in transcription, and these have been retracted back into the central nucleoid. Similar changes in bacterial fine structure were noted when transcription was inhibited due to overproduction of the nucleoid protein H-NS (Spurio et al., 1992).

In chloramphenicol-treated cells a high level of cytoplasmic labelling is retained at a time when genomic DNA has been almost entirely removed from this part of the cell, suggesting that in this situation most GyrA and GyrB molecules outside the nucleoid are not DNAassociated. Similar results were obtained by Durrenberger et al. (1988) for HU protein.

\section{General conclusions}

The results obtained in this study indicate that GyrA and GyrB proteins in E. coli are largely present outside the nucleoid, where they are localized within the cytoplasm. Total probe counts indicate levels of at least 1000-3000 molecules of GyrA and GyrB per cell. This is considerably greater than would be expected if these proteins were only present within the 50 or so active DNA gyrase complexes that have been demonstrated in the living cell (see Introduction), suggesting that most of these proteins may be present within the bacterium as inactive subunit pools.

Within the cytoplasmic pool GyrA and GyrB proteins do not appear to be associated with each other and there is no general localization in relation to the nucleoid boundary.
If cytoplasmic (transcriptive) DNA occurs mainly at the edge of the nucleoid, this lack of localization would suggest that most of the cytoplasmic gyrase proteins are not DNA-associated. This is corroborated by analysis of the chloramphenicol-treated cells, where high levels of GyrA and $G y r B$ proteins are still present within cytoplasm that has lost most (if not all) of its genomic DNA.

\section{ACKNOWLEDGEMENTS}

The authors are grateful to the Wellcome Trust for supporting the studies carried out in this investigation (Grant No. 03355/1.5). A. M. is a Lister Institute Jenner Fellow. B. D. was supported by Glaxo-Group Research.

\section{REFERENCES}

Beesley, J. E. (1985). Colloidal gold: a new revolution in marking cytochemistry. Proc R Microsc Soc 20, 187-196.

Bohrmann, B., Villiger, W., Johansen, R. \& Kellenberger, E. (1991). Corraline shape of the bacterial nucleoid after cryofixation. $J$ Bacteriol 173, 3149-3158.

Bukua, B., Reilly, P., McCarty, J. \& Walker, G. C. (1993). Immunogold localization of the DnaK heat shock protein in Escherichia coli cells. J Gen Microbiol 139, 95-99.

Cloeckaert, A., Zygmunt, M. S., de Wergifosse, P., Dubray, G. \& Limet, J. N. (1992). Demonstration of peptidoglycan-associated Brucella outer-membrane proteins by use of monoclonal antibodies. $J$ Gen Microbiol 138, 1543-1550.

Drlica, K. \& Rouviere-Yaniv, J. (1987). Histone-like proteins of bacteria. Microbiol Rev 51, 301-319.

Durrenberger, M., Bjornski, M. A., Vetz, T., Hobot, J. A. \& Kellenberger, E. (1988). Intracellular location of the histone-like protein HU in Escherichia coli. J Bacteriol 170, 4757-4768.

Durrenberger, M., La Teana, A., Citro, G., Venanzi, F., Gualerzi, C. O. \& Pon, C. L. (1991). Escherichia coli DNA-binding protein H-NS is localised in the nucleoid. Res Microbiol 142, 373-380.

Harlow, E. \& Lane, D. (1988). Antibodies. A Laboratory Manual. Cold Spring Harbour, NY: Cold Spring Harbor Laboratory.

Higgins, C. F., Hinton, J. D., Hulton, C. J., Owen-Hughes, T., Pavitt, G. D. \& Seirafi, A. (1990). Protein H1 : a role for chromatin structure in the regulation of bacterial gene expression and virulence? Mol Microbiol 4, 2007-2012.

Hobot, J. A. (1989). Lowicryls and low-temperature embedding. In Colloidal Gold: Principles, Methods and Applications. Edited by M. A. Hyat. San Diego: Academic Press.

Hobot, J. A., Bjornski, M. A. \& Kellenberger, E. (1987). Use of onsection immunolabelling and cryosubstitution for studies of bacterial DNA distribution. J Bacteriol 169, 2055-2062.

Hobot, J. A. \& Newman, G. R. (1991). Strategies for improving the cytochemical and immunocytochemical sensitivity of ultrastructurally well-preserved, resin-embedded biological tissue for light and electron microscopy. Scanning Microsc Suppl. 5, 27-41.

Horisberger, M. (1992). Colloidal gold and its application in cell biology. Int Rev Cytol 136, 227-287.

Kavenoff, R. \& Ryder, O. (1976). Electron microscopy of membrane-associated folded chromosomes of Eschericbia coli. Chromosoma 55, 13-25.

Kroncke, K. D., Boulnois, G., Roberts, I., Bitter-Suermann, D., Golecki, J. R., Jann, B. \& Jann, K. (1990). Expression of the Escherichia coli $\mathrm{K} 5$ capsular antigen: immunoelectron microscopic 
and biochemical studies with recombinant E. coli. J Bacteriol 172, 1085-1091.

Maxwell, A. \& Gellert, M. (1984). The DNA dependence of the ATPase activity of DNA gyrase. J Biol Chem 259, 14472-14480.

Reece, R. J. \& Maxwell, A. (1991). DNA gyrase: structure and function. Crit Rev Biochem Mol Biol 26, 335-375.

Snyder, M. \& Drlica, K. (1979). DNA gyrase on the bacterial chromosome: DNA cleavage induced by oxolinic acid. $J$ Mol Biol $131,287-302$.
Spurio, R., Durrenberger, M., Falconi, M., La Teana, A., Pon, C. L. \& Gualerzi, C. O. (1992). Lethal overproduction of the Escherichia coli nucleoid protein H-NS: ultramicroscopic and molecular autopsy. Mol \& Gen Genet 231, 201-211.

Worcel, A. \& Burgi, E. (1972). On the structure of the folded chromosome of Escherichia coli. J Mol Biol 71, 127-147.

Received 25 October 1993; revised 16 March 1994; accepted 22 March 1994. 